\title{
In-situ investigation on fatigue behaviors of Ti-6Al-4V manufactured by selective laser melting
}

\author{
Guian Qian $^{\mathrm{a}, \mathrm{b}, *}$, Zhimo Jian ${ }^{\mathrm{a}, \mathrm{b}}$, Xiangnan Pan ${ }^{\mathrm{a}, \mathrm{b}}$, Filippo Berto ${ }^{\mathrm{c}}$ \\ ${ }^{a}$ State Key Laboratory of Nonlinear Mechanics (LNM), Institute of Mechanics, Chinese Academy of Sciences, Beijing 100190, China \\ ${ }^{\mathrm{b}}$ School of Engineering Science, University of Chinese Academy of Sciences, Beijing 100049, China \\ ${ }^{\mathrm{c}}$ Department of Mechanical and Industrial Engineering, Norwegian University of Science and Technology (NTNU), Richard Birkelands vei $2 b$, 7491 Trondheim, Norway
}

\section{A R T I C L E I N F O}

\section{Keywords:}

Selective laser melting

In-situ SEM

Ti-6Al-4V

Low cycle fatigue

Crack propagation

\begin{abstract}
A B S T R A C T
In-situ fatigue tests were conducted for exploring the fatigue crack propagation process for Ti-6Al-4V manufactured by selective laser melting (SLM). Fatigue specimens were prepared with two printing orientations by SLM and characterized by scanning electron microscopy (SEM). In-situ fatigue experiments were carried out at $25{ }^{\circ} \mathrm{C}, 200{ }^{\circ} \mathrm{C}, 400{ }^{\circ} \mathrm{C}$ and $600{ }^{\circ} \mathrm{C}$, respectively. Results show that vertically printed specimens have more and larger defects than horizontally printed ones. The fatigue property of horizontally printed specimens is better than that of vertically printed specimens. The anisotropy caused by printing orientation is the reason for the difference in fatigue property. Crack propagation rate increases with temperature. A large number of secondary cracks occurred during the crack propagation at elevated temperature. The branching of secondary cracks releases the energy at the crack tip, and thus slows down the crack growth.
\end{abstract}

\section{Introduction}

Additive manufacturing (AM) technology refers to a kind of technology that directly processes parts by layers according to three-dimensional (3D) digital model, which is also called 3D printing, direct digital manufacturing, rapidly prototyping, etc. It is a new frontier technology developed in the late $1980 \mathrm{~s}$ and it is considered as one of the major breakthroughs in manufacturing technology fields. It is considered that the new manufacturing technology will promote the third industrial revolution [1]. In contrast to traditional metal manufacturing processes, AM is becoming an innovative technology for designing new products with unprecedented complexity [2]. ASTM (American Society for Testing Materials) defines AM as the process of connecting materials from 3D model data to create objects, usually layer by layer, rather than subtraction [3]. In addition, AM technology does not require molds, which substantially reduces the cost and increases the flexibility of production of complex components [4]. Therefore, the development of AM technology has been widely recognized in biomedicine, aerospace, automobile, marine and offshore industries [5]. Compared to the static strength and stiffness, investigations on the dynamic performances of AM materials and structures are quite limited. Considered as promising lightweight structural materials for aerospace and automobile industrial sections [6], the static mechanical properties of $\mathrm{AM}$ Ti-6Al-4V alloys are explored in recent years, such as strength, stiffness, impact energy etc. [7]. However, the fatigue performances and failure mechanisms are not yet well understood. Therefore, it is necessary to understand the mechanical properties of the AM materials in order to fully adopt this approach for structural bearing components, especially under fatigue loadings.

As early as the development of AM technology in the $1990 \mathrm{~s}$, researchers tried to prepare non-metallic prototypes based on various rapid prototyping manufacturing methods, and achieved the preparation of metal parts through the follow-up process [8]. Compared with the rapid prototyping manufacturing technologies such as stereo light forming (SLA), laminated manufacturing (LOM), fused deposition forming (FDM), selective laser sintering (SLS) provided a most direct possibility for preparing metal parts due to its characteristics of using powder materials [9]. With the application of high power laser in rapid prototyping technology, SLS technology was further developed to selective laser melting technology (SLM), which is a process of melting and cooling metal powder rapidly by high energy lasers. The process is based on the interaction between laser and powder which includes a series of physical and chemical processes such as energy transfer and phase change. SLM has been widely employed for manufacturing metals, such as Ti-6Al-4V, AlSi10Mg and Inconel 718 alloys [10]. The development of SLM technology has brought infinite vitality to manufacturing industry, especially to the development of rapid processing, personalized medical products, aerospace parts and automotive parts

\footnotetext{
* Corresponding author.

E-mail address: qianguian@imech.ac.cn (G. Qian).
} 
Table 1

Nominal chemical composition of the Ti-6Al-4Vspecimens (wt. \%).

\begin{tabular}{|c|c|c|c|c|c|c|c|c|c|c|c|}
\hline Element & $\mathrm{Ti}$ & $\mathrm{Al}$ & $\mathrm{V}$ & $\mathrm{Fe}$ & $\mathrm{Ti}$ & $\mathrm{Cr}$ & $\mathrm{Cu}$ & Mn & $\mathrm{Ni}$ & $\mathrm{Mg}$ & $\mathrm{Zn}$ \\
\hline wt. \% & Balance & 6.75 & 4.0 & 0.25 & 0.011 & $<0.01$ & $<0.01$ & $<0.01$ & $<0.01$ & $<0.01$ & $<0.01$ \\
\hline
\end{tabular}

manufacturing industry [11]. At present, the main issue associated with Ti-6Al-4V manufactured by SLM is assessment and estimation of the related fatigue performances [12-20].

Some recent investigations have been carried out on Ti-6Al-4V manufactured by SLM, and the corresponding manufacturing parameters have been studied. Bastien et al. [21] investigated the effects of the surface roughness of Ti-6Al-4V parts produced by SLM on high cycle fatigue (HCF) behavior, showing that the HCF life is significantly reduced due to the effect of surface roughness. Zhang et al. [22] proposed a general simulation framework to predict the metallurgical properties of AM parts. The comparison between experimental and numerical predictions shows that such modeling techniques, with minimal calibration effort, can be used to predict strength behavior, including softening beyond the uniform extension limit. Victor et al. [23] compared the fatigue properties of $\mathrm{Ti}-6 \mathrm{Al}-4 \mathrm{~V}$ specimens fabricated by electron beam melting (EBM) and SLM, showing that the AM specimens have better fatigue property with the elimination of surface defects. Dzugan et al. [24] investigated the effect the orientation and thickness of Ti-6Al-4V samples on their microstructures and tensile properties, showing that the microstructures and mechanical properties are related to the building direction, and partly to the thickness and location of the chamber in the samples. Benedetti et al. [25] carried out low and HCF tests on Ti-6Al-4V specimens manufactured by SLM after low temperature stress relief treatment, showing that average stress, residual stress and defects have important effects on fatigue properties. However, only a few studies have been carried out to address the fatigue performance of components manufactured by SLM [26-30]. Therefore, this paper aimed at partially filling this gap, by investigating the fatigue property of Ti-6Al-4V parts manufactured by SLM. This is of significant interest for many industrial applications and would allow the design of safer products and components subjected to cyclic loadings [31-33].

As a powerful tool for surface topography and microstructure characterization, in-situ scanning electron microscopy (SEM) was used for observing fracture morphology, to study fatigue crack initiation. Wang et al. [34] carried out in-situ fatigue tests using SEM at room and elevated temperatures, showing that the effect of pore is more pronounced at low temperature, and when the temperature is higher than $400{ }^{\circ} \mathrm{C}$, temperature influence is dominant. Han et al. [35] observed the slip line and crack initiation during fretting fatigue of nickel-based single alloys and predicted the location and direction of crack initiation. Zhang et al. [36] studied the fatigue crack initiation and propagation behavior of a high Niobium (Nb) titanium (Ti) alloy with near-layered structure at $750{ }^{\circ} \mathrm{C}$, showing that the fatigue cracks initiate at the center of the notch and then transfer to the edge. Lu et al. [37] investigated the stress-induced martensitic transformation of copper-nickel-aluminum shape memory alloys and its relationship with crack nucleation and propagation, and found that the stress concentration at the crack tip can lead to accumulation defects and the formation of different types of martensite. Yan et al. [38] studied the deformation behavior and fracture mechanism of $12 \mathrm{Cr} 1 \mathrm{MoV}$ steel, showing that slip dominates and it is not affected by microstructure. In addition, Gallo et al. [39] extended the averaged strain energy density (SED) method to the assessment of fatigue behavior for the notched components. Fracture toughness of silicon is evaluated in [40] and compared with that of pre-cracked specimens as well as notched specimens. Gallo et al. [41] investigated the fracture behavior of silicon at nanoscale using the theory of critical distances (TCD) and demonstrates that TCD can well quantify the fracture behavior. Moreover, it is suggested that the TCD is an alternative strategy for the determination of $K_{\mathrm{Ic}}$ at the nanoscale. Chai et al. [42] investigated the slip and propagation of fatigue cracks by in-situ SEM, and found that crack deformation and crack branching significantly reduce the crack growth rate. In-situ SEM is an effective method to study the fatigue performance and crack propagation of Ti$6 \mathrm{Al}-4 \mathrm{~V}$ alloy.

Therefore, in-situ fatigue experiments using SEM are performed in this paper for studying the fatigue performance of Ti-6Al-4V manufactured by SLM. Fatigue test samples were prepared with two building orientations (horizontally printed, vertically printed), and characterized by SEM. In-situ fatigue experiments $(\mathrm{f}=10 \mathrm{~Hz}$ ) were carried out at $25{ }^{\circ} \mathrm{C}, 200{ }^{\circ} \mathrm{C}, 400{ }^{\circ} \mathrm{C}$ and $600{ }^{\circ} \mathrm{C}$ in order to study the fatigue behavior, microstructure evolution and crack propagation. After observing fracture surfaces, the crack initiation mechanism was discussed and the Paris model was used to quantify crack propagation.

\section{Material, specimens and SLM parameters}

In this section, material, specimen design, SLM technology and related processing parameters are described in detail.

\subsection{Material}

The Ti-6Al-4V materials were fabricated using an EOS M290 machine, which is a SLM system from EOS GmbH. Raw material powders were certified with particle sizes ranging from 20 to $50 \mu \mathrm{m}$. The chemical composition of material is listed in Table 1.

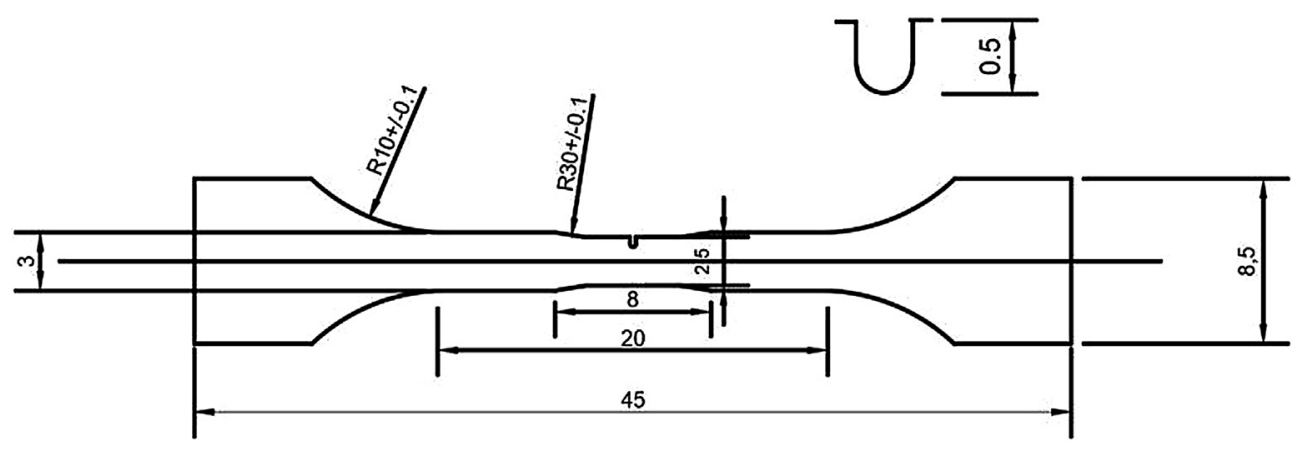

Fig. 1. Geometry of the Ti-6Al-4V specimen used in fatigue test (unit: $\mathrm{mm}$ ). 


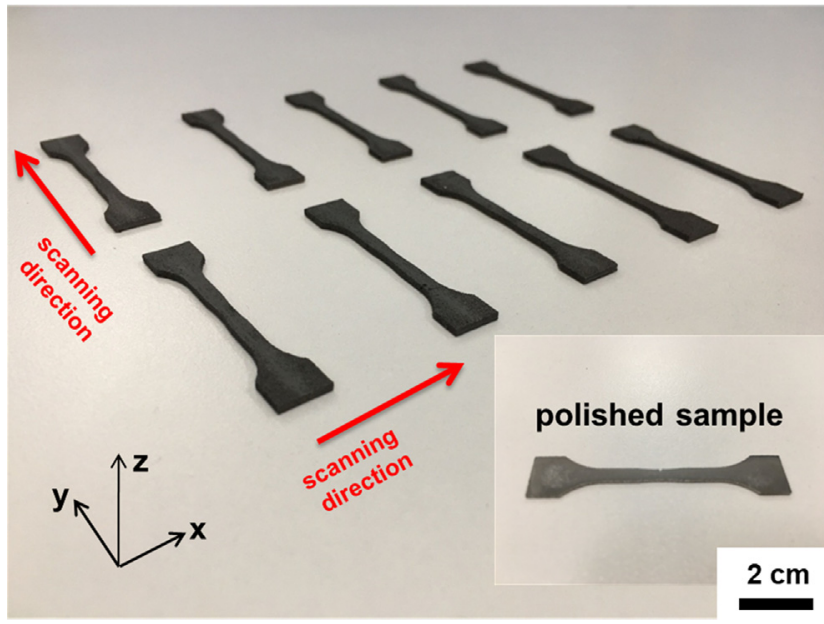

Fig. 2. As printed harvested Ti-6Al-4V samples for in-situ SEM fatigue experiments.

\subsection{Specimens}

The design of Ti-6Al-4V sample is according to the Chinese code GB/T 228-2002 [43]. The geometry of Ti-6Al-4V specimen used in fatigue test was shown in Fig. 1. The U-shaped notch located at the center of the gauge section was specially designed for the study of crack initiation. During the SLM process, the average laser power was $357 \mathrm{~W}$ and the specimens were built on a plate pre-heated to $80^{\circ} \mathrm{C}$.

This test included two batches of samples, i.e. one batch of horizontally printed samples (10 specimens) and the other batch of vertically printed ones (10 specimens). In order to obtain the smooth surface, these samples were polished using $\mathrm{SiC}$ paper. The processing parameters of horizontally and vertically printed samples were consistent during SLM process. The final harvested specimens had a thickness of $0.7 \mathrm{~mm}$. The as-printed harvested Ti-6Al-4V samples for insitu SEM fatigue experiment are shown in Fig. 2, where the arrow represents the printing direction. On the top are the vertically printed samples, below are the horizontally printed ones.

\subsection{SLM parameters}

SLM is a process of melting and cooling a metal powder rapidly using a high-power laser. The process is based on the interaction between laser and powders, which includes a series of physical and chemical processes, such as energy transfer and phase change. The related SLM processing parameters used in this paper are listed in Table 2.

\section{Experimental procedure}

In this section, the in-situ fatigue test process, fractography and SEM observation are described.

\subsection{Fatigue test}

In-situ fatigue tests were conducted in the SEM chamber with an electro hydraulic servo system at elevated temperatures. The In-situ SEM fatigue experiment system is shown in Fig. 3. The Ti-6Al-4V

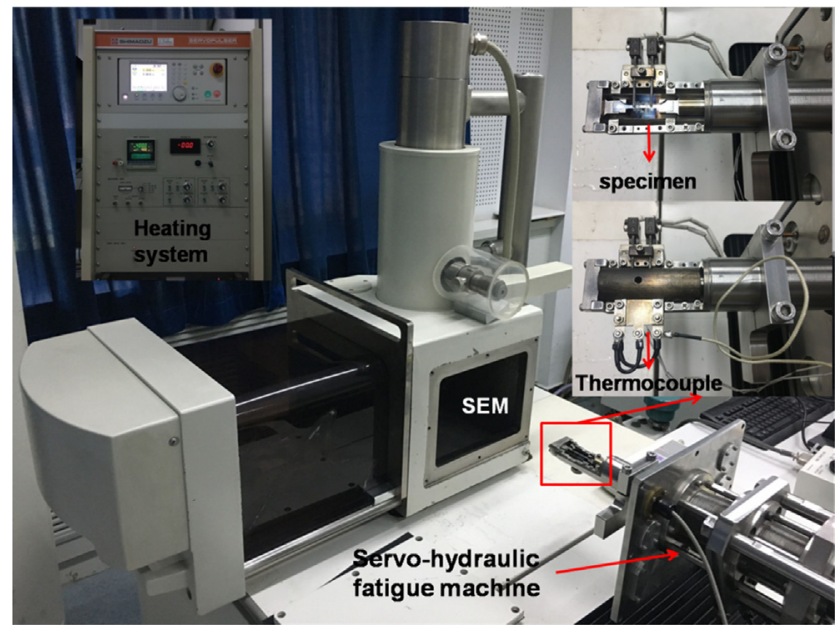

Fig. 3. In-situ SEM fatigue experiment system operated at elevated temperatures.

sample was heated by thermal radiation in the vacuum chamber which could heat the sample up to $800{ }^{\circ} \mathrm{C}$ with temperature control accuracy of $\pm 2{ }^{\circ} \mathrm{C}$ [44]. The temperature precision was achieved by thermocouple. In this paper, fatigue experiments were conducted at $25{ }^{\circ} \mathrm{C}$, $200{ }^{\circ} \mathrm{C}, 400{ }^{\circ} \mathrm{C}$ and $600{ }^{\circ} \mathrm{C}$ with the maximum loading frequency of $10 \mathrm{~Hz}$. The peak stress was $300 \mathrm{MPa}$ at the stress ratio $\mathrm{R}=0.2$. SEM was used to record the process of crack initiation and propagation.

\subsection{Microstructure characterization}

In this paper, the crack propagation mechanism was studied by observing the fracture morphology of Ti-6Al-4V samples using SEM. It is shown in Fig. 4 the microstructures of Ti-6Al-4V specimens manufactured by SLM. The sample shows lamellar microstructures with $\alpha$ lamellar thickness between 1 and $2 \mu \mathrm{m}$. The results are consistent with those reported in [21].

\section{Results and discussion}

This section mainly discusses the in-situ observation of fatigue crack initiation and propagation, fractography, comparison of fatigue properties between horizontally printed and vertically printed samples, and calculation with the Paris model.

\subsection{Crack initiation and propagation}

It is shown in Fig. 5 the in-situ test results for vertically printed sample tested at different temperatures. As described in Section 2.3, the scanning speed and the hatching distance of the laser were $1260 \mathrm{~mm} / \mathrm{s}$ and $0.17 \mathrm{~mm}$, respectively. The shape of melt pool remained unchanged during scanning. When scanning along a certain direction, large unfused defects and porosity (holes) were formed inevitably, as shown in Fig. 5a. The holes play an important role in fatigue performance of Ti$6 \mathrm{Al}-4 \mathrm{~V}$ specimens manufactured by SLM, and the hole near the notch seriously affects the fatigue life of the specimens. It is shown that a main crack rapidly developed into fracture after 38 loading cycles. Fig. 5b, c shows the in-situ fatigue test results at $200{ }^{\circ} \mathrm{C}$ and $400{ }^{\circ} \mathrm{C}$,

Table 2

SLM manufacturing parameters of the Ti-6Al-4V specimens.

\begin{tabular}{|c|c|c|c|c|c|c|c|}
\hline $\begin{array}{l}\text { Laser power } \\
{[\mathrm{W}]}\end{array}$ & $\begin{array}{l}\text { Scanning speed } \\
{[\mathrm{mm} / \mathrm{s}]}\end{array}$ & $\begin{array}{l}\text { Scanning spacing } \\
{[\mathrm{mm}]}\end{array}$ & $\begin{array}{l}\text { Preheating temperature } \\
{\left[{ }^{\circ} \mathrm{C}\right]}\end{array}$ & $\begin{array}{l}\text { Powder size } \\
{[\mathrm{mm}]}\end{array}$ & $\begin{array}{l}\text { Printing direction } \\
{\left[{ }^{\circ}\right]}\end{array}$ & Laser profile & $\begin{array}{l}\text { Laser focal spot diameter } \\
{[\mu \mathrm{m}]}\end{array}$ \\
\hline 357 & 1260 & 0.17 & 80 & 0.02 & 0,90 & Gaussian & $20-50$ \\
\hline
\end{tabular}



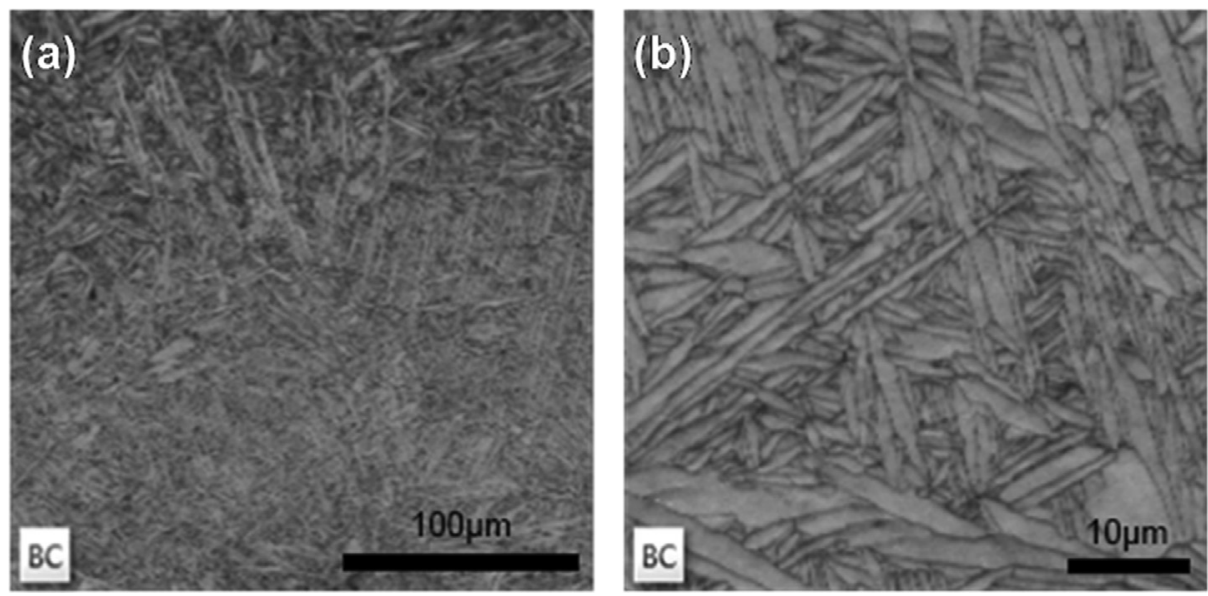

Fig. 4. Microstructure of the Ti-6Al-4V specimen manufactured by SLM.

respectively. No crack propagation occurred after 80,024 and 120,879 cycles. This indicates that the studied Ti-6Al-4V specimens in general have quite good fatigue property at high temperatures, and the temperature effect on crack growth is relatively small at low cycle fatigue [34].

It is shown in Fig. 6 the crack propagation process for vertically printed sample tested at room temperature $\left(25^{\circ} \mathrm{C}\right)$. At room temperature, Ti-6Al-4V specimen shows a smaller grain size with $\alpha$-lamellar thickness between 1 and $2 \mu \mathrm{m}$ as demonstrated in Fig. 4. Material brittleness is obvious and the dislocation resistance at the grain boundary is large, which makes crack propagation along different crystal planes near the tip. When the fatigue cycle is 2809 , crack A started to appear around the U-shaped notch. With the increase of loading cycles, crack A developed into the dominant crack quickly. Meanwhile, the length of internal crack B near the dominant crack A gradually increases. When the number of fatigue loading cycle reaches 5208, main crack A and the inner crack B suddenly penetrated, and coalescenced into one main crack, thus leading to the global failure of the sample at loading cycle of 6025 (not shown here).

It is shown in Fig. 7 the crack propagation process for vertically printed sample tested at $400{ }^{\circ} \mathrm{C}$. It is seen that there is a hole near the notch and the fatigue crack growth is affected by the local microstructures. The holes made crack initiation and propagation biased, so that crack initiation and propagation occurred in the direction towards the hole. When the loading cycle reaches 23903 , micro-cracks started to develop at the upper edge of notch, until the fatigue loading is 25,635 cycles. Then the crack propagated rapidly and failed at the cycles of 27309. Therefore, the inhomogeneity of local structures such as defects and inclusions can change the crack growth path and reduce the crack growth rate, especially in the final stage of crack growth.

It is shown in Fig. 8 the micro crack propagation process for horizontally printed sample tested at $600{ }^{\circ} \mathrm{C}$. Under high temperature
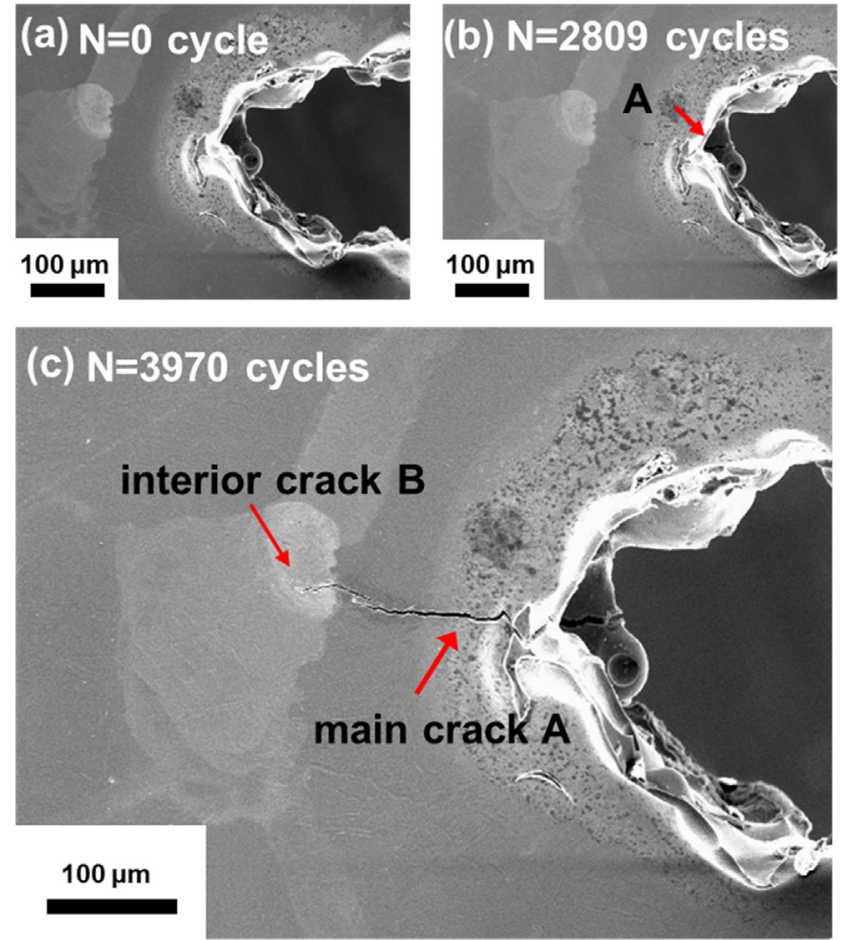

Fig. 6. The fatigue crack propagation process for vertically printed Ti-6Al-4V sample at room temperature: (a) $\mathrm{N}=0$ cycle; (b) $\mathrm{N}=2809$ cycles; (c) $\mathrm{N}=3970$ cycles.
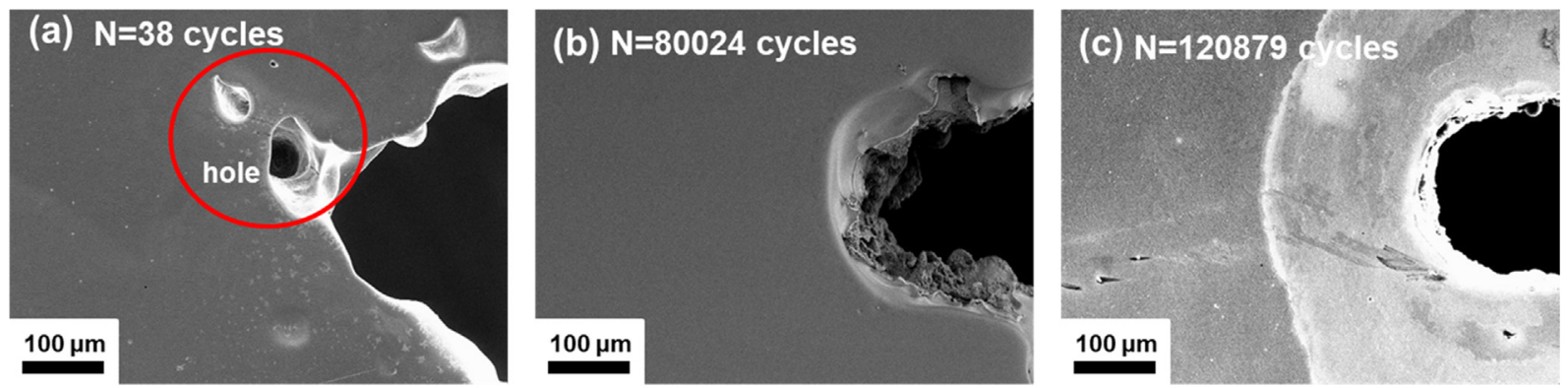

Fig. 5. The In-situ fatigue tests for vertically printed Ti-6Al-4V sample tested at different temperatures: (a) $25{ }^{\circ} \mathrm{C}, \mathrm{N}=38$ cycles: crack propagation rapidly; (b) $200{ }^{\circ} \mathrm{C}, \mathrm{N}=80024$ cycles: non crack propagation; (c) $400{ }^{\circ} \mathrm{C}, \mathrm{N}=120879$ cycles: non crack propagation. 

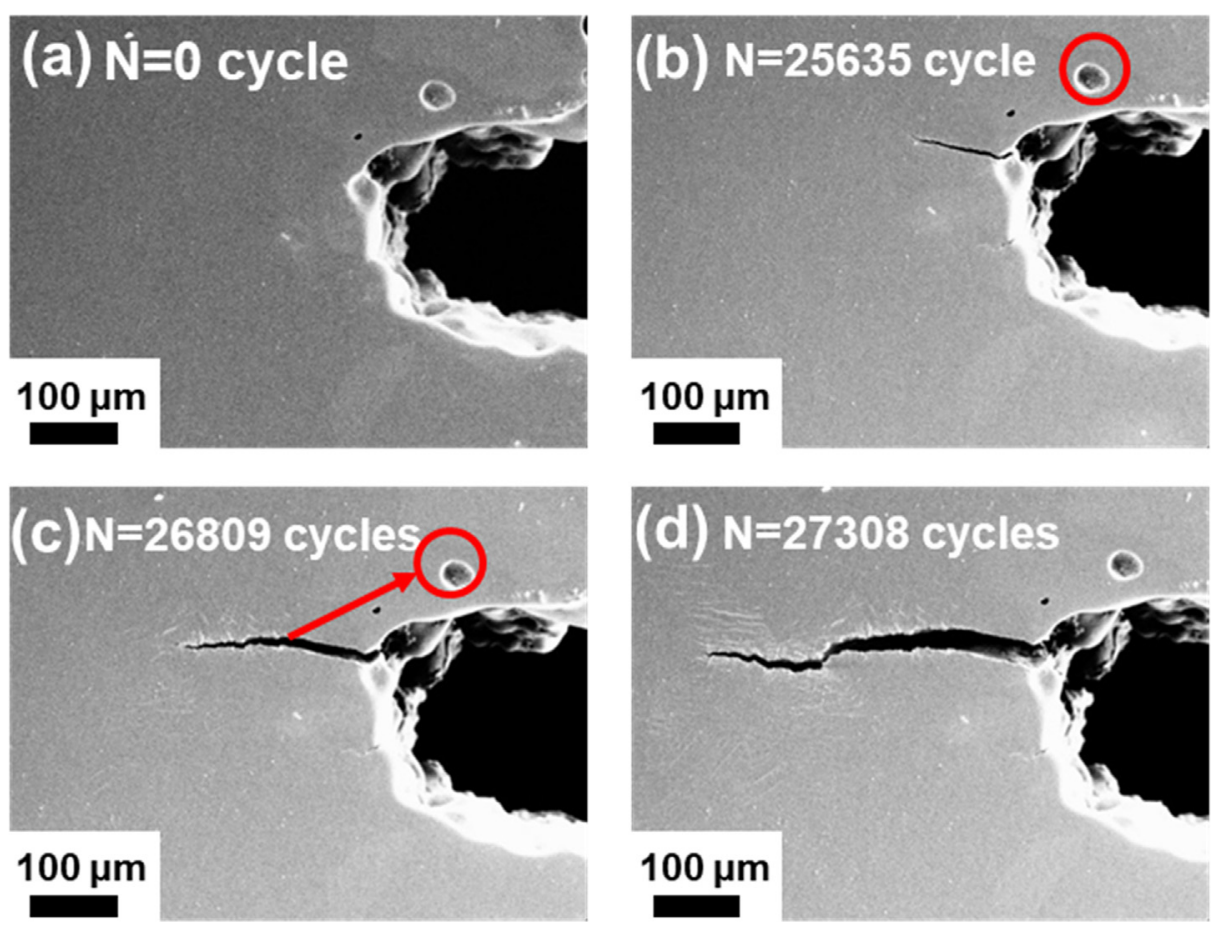

Fig. 7. The fatigue crack propagation process for vertically printed Ti-6Al-4V sample at $400{ }^{\circ} \mathrm{C}$ : (a) $\mathrm{N}=0$ cycle; (b) $\mathrm{N}=25635$ cycles; (c) $\mathrm{N}=26809$ cycles; (d) $\mathrm{N}=27308$ cycles.

environment, the material is oxidized, forming a large number of oxidation products which will generally promote the generation of crack nucleation and sliding, weaken the binding force of grain boundary, and accelerate the crack growth process. However, for Ti-6Al-4V manufactured by SLM, crack propagation rate is quite slow. This is because that the secondary crack releases the energy at the crack tip which increases the fracture toughness and slows down the crack growth rate. The micro-cracks began to appear at loading cycle of 19533 and propagated steadily with the loading cycles. When fatigue cycle reaches 20009 , the micro crack opened slightly near the notch edge of main crack, and there are many dispersed micro cracks around the notch. As already discussed above, the appearance of secondary cracks at high temperature is beneficial to slow down the crack propagation. As shown in Fig. 8, a secondary crack occurred during crack propagation at high temperature. The branching of secondary cracks released the energy at the crack tip, which slows down the crack growth. Finally, the sample failed at loading cycles of 21659.

\subsection{Characteristics of crack origins}

This section summarizes fatigue crack origins and SEM was used to observe the fracture morphology in order to study fatigue crack propagation mechanism.

It is shown in Fig. 9 the fracture surface of vertically printed sample (Ti-6Al-4V) at room temperature of $25{ }^{\circ} \mathrm{C}$. It is seen that there is a large defect near the notch. The cleavage of phase $\alpha$ appeared only above the hole while none below the notch. It is summarized that significant microstructure differences around the hole are due to the combination of cyclic loading and defects generated in the SLM process.

In general, fatigue failure process includes three stages: crack initiation, stable crack propagation and instantaneous fracture. Fig. 10 shows the fracture surface for horizontally printed sample tested at $200{ }^{\circ} \mathrm{C}$. From this figure, the crack propagation is divided into three regions. Firstly, $\alpha$ phase cleavaged around notch and crack initiation started. Then crack propagated near notch and finally fracture area
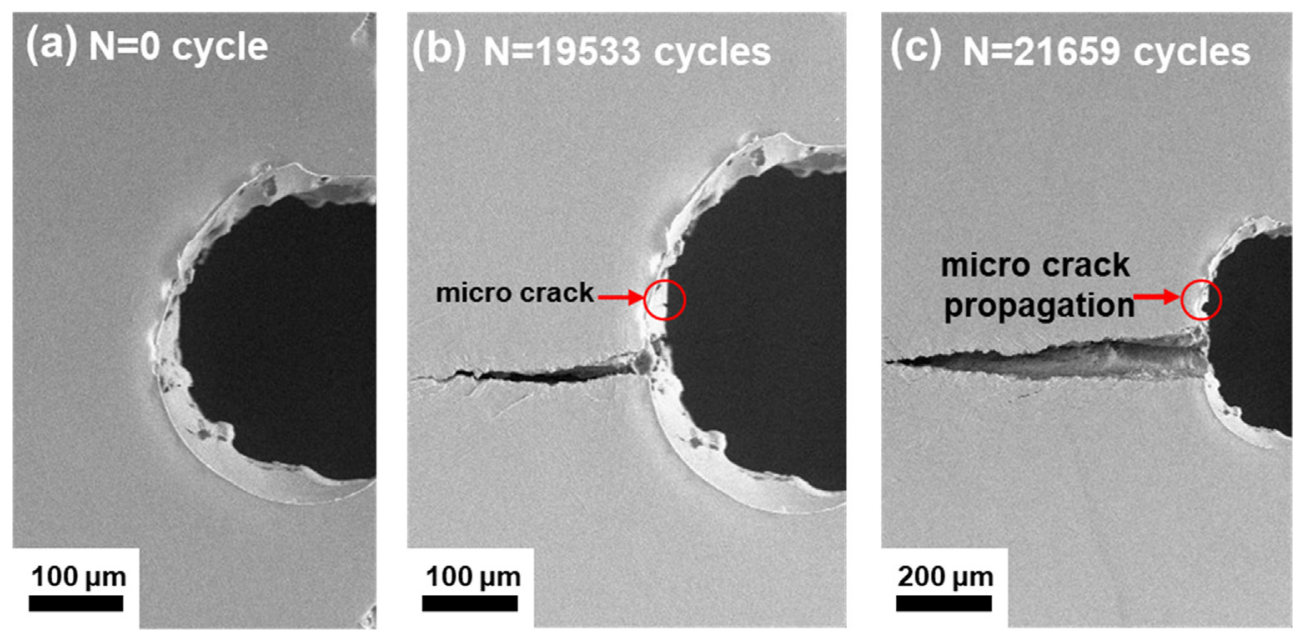

Fig. 8. The micro crack propagation process for horizontally printedTi- $6 \mathrm{Al}-4 \mathrm{~V}$ sample at $600{ }^{\circ} \mathrm{C}$ : (a) $\mathrm{N}=0$ cycle; (b) $\mathrm{N}=19533 \mathrm{cycles}$; (c) $\mathrm{N}=21659$ cycles. 


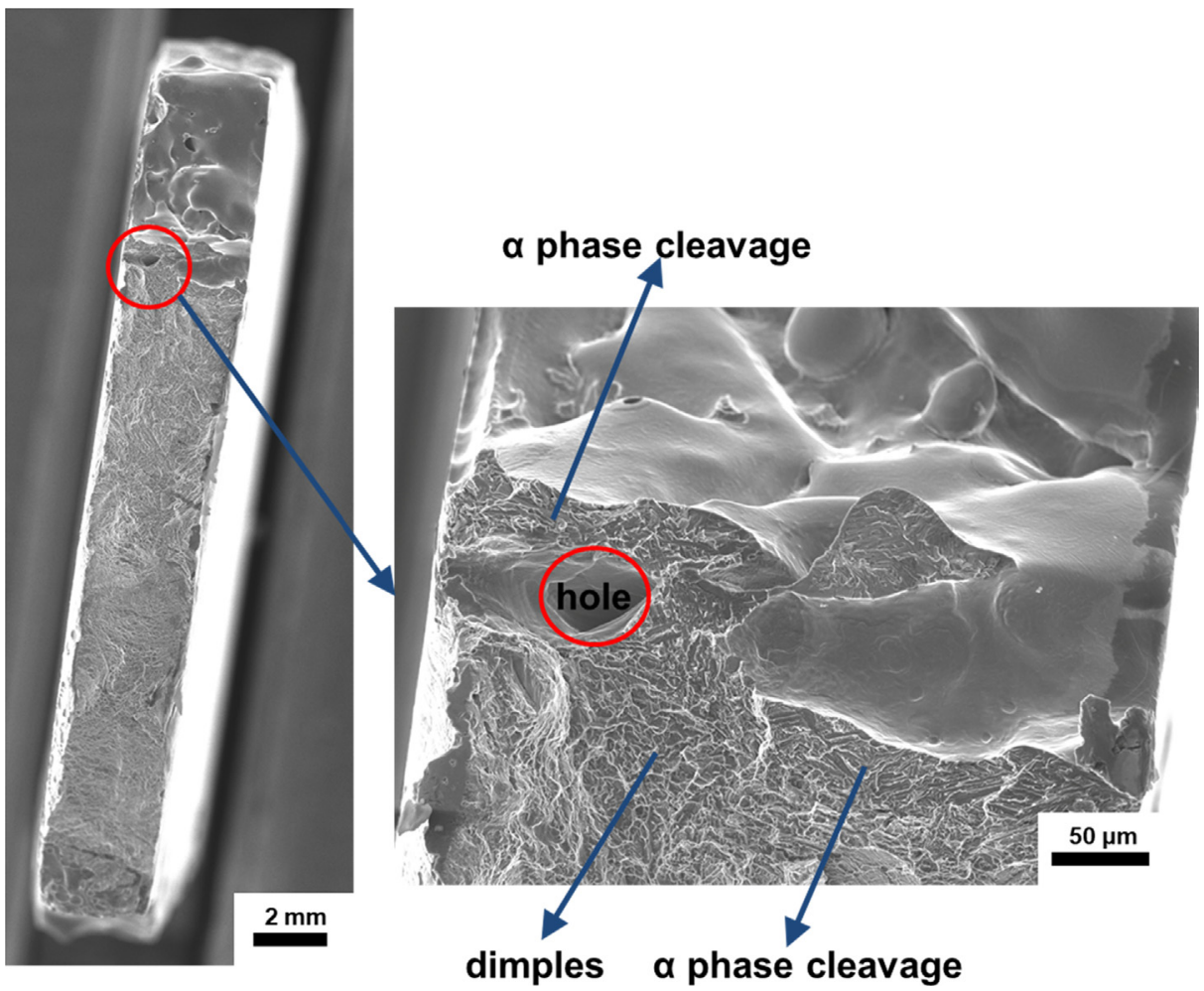

Fig. 9. The fracture surface for vertically printed Ti-6Al-4V sample at $25^{\circ} \mathrm{C}$.

occurred from notch instantaneously. With the increase of temperature, the portion of crack propagating stage increases gradually. The life of the instantaneous fracture zone of vertically printed samples is shorter than that of the horizontal printed samples, which is due to the printing defects. From Fig. 10, the appearance of multi-crack initiation can be found in horizontally printed specimens at high temperature. The crack origin zone at the left lower part (C.O. 1) is a defect formed in the SLM process. This printing defect acted also as the origin of crack initiation. To summarize, defects formed in the SLM process affect the crack propagation behavior significantly.

It is seen in Fig. 11 the fracture surface for vertically printed sample tested at $600{ }^{\circ} \mathrm{C}$. There are a large number of unmelted particles inside the U-shaped notch which significantly reduced the fatigue performance of vertically printed samples.

It is shown in Fig. $11 \mathrm{a}, \mathrm{b}$ that there are a lot of defects in crack propagation area, which results in the decrease of fatigue performance. By comparing the fracture surfaces, it is found that the vertically printed samples have more and larger defects, voids and unmelted

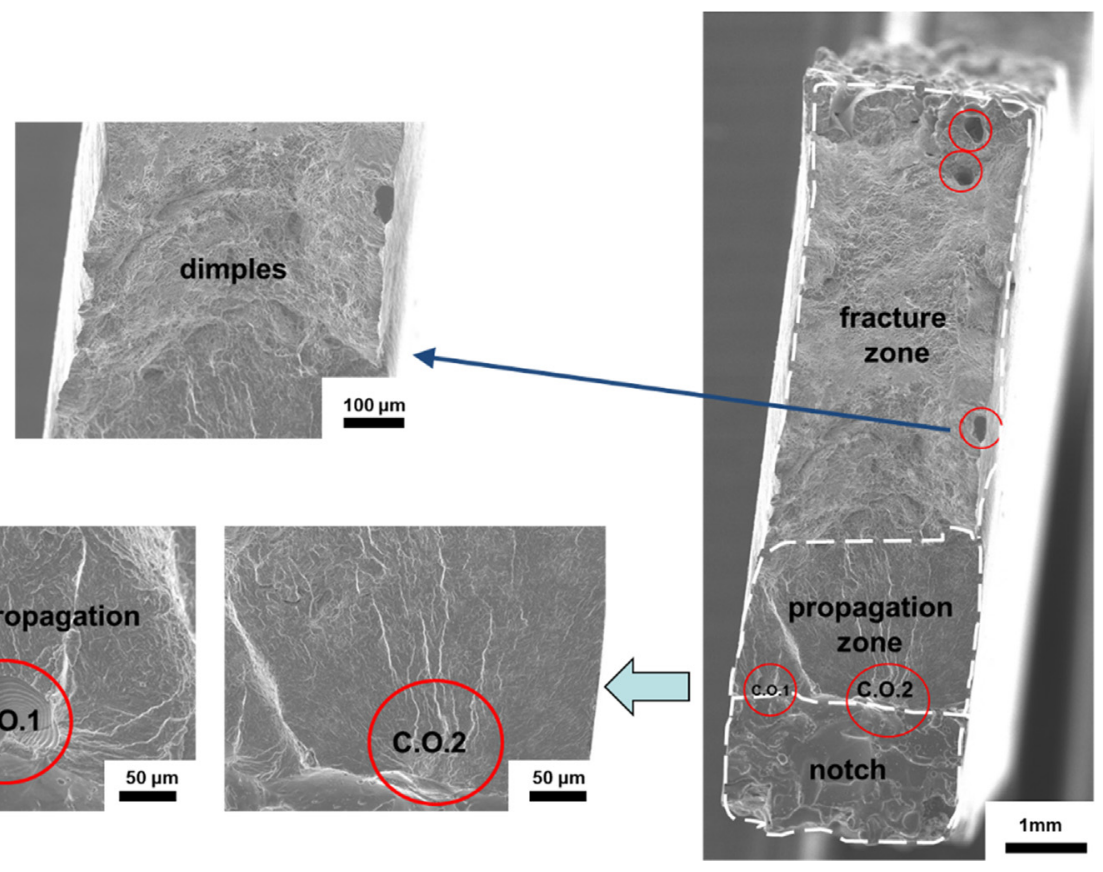

Fig. 10. The fracture surface for horizontally printedTi-6Al-4V sample at $200{ }^{\circ} \mathrm{C}$, C.O. indicates crack origin. 


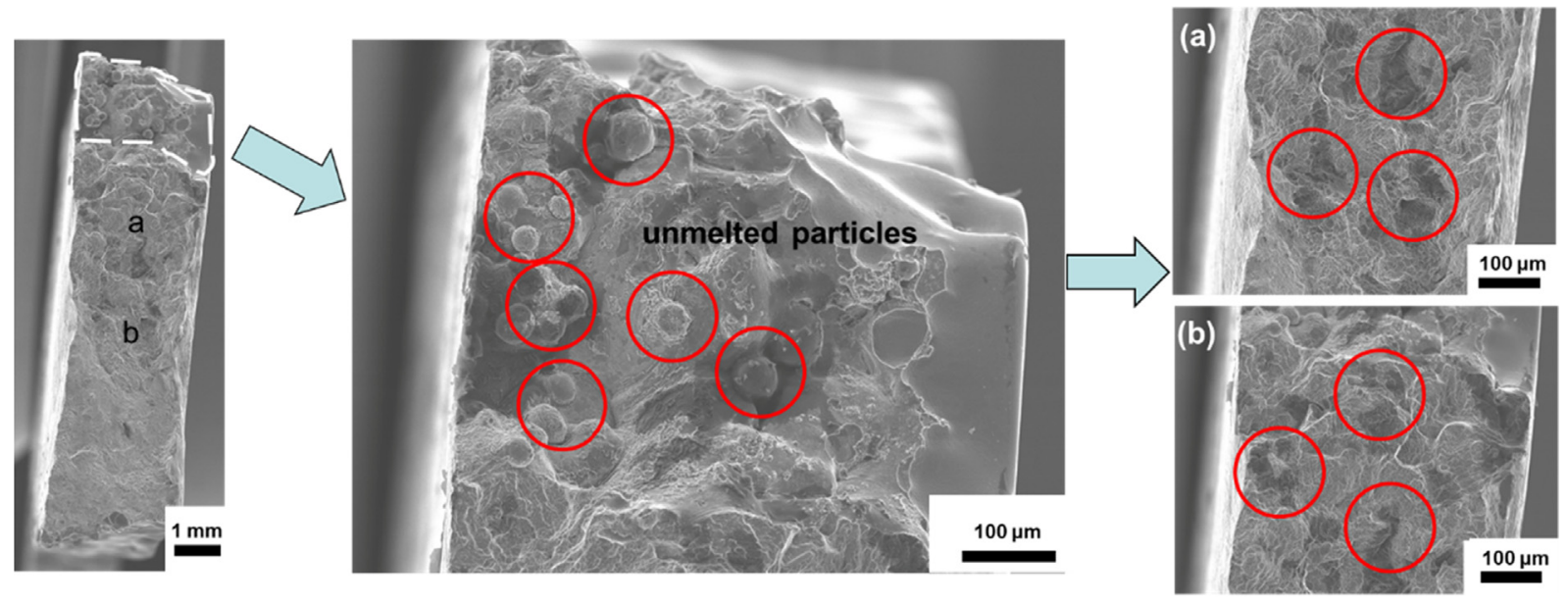

Fig. 11. The fracture surface for vertically printedTi-6Al-4V sample tested at $600{ }^{\circ} \mathrm{C}$.

particles than those of horizontally printed samples, which is the fundamental reason for the difference of fatigue properties between the two specimens.

\subsection{Fatigue life and crack propagation rate}

In this study, in-situ fatigue tests were carried out for both horizontally and vertically printed specimens at different temperatures. The relationship between fatigue cycle and temperature for all the specimens is shown in Fig. 12. It can be seen that the average crack growth rate is the lowest at $25{ }^{\circ} \mathrm{C}$, and the average crack growth rate reaches maximum at $600{ }^{\circ} \mathrm{C}$. Crack growth rate increases with temperature. In addition, the fatigue properties of horizontally printed specimens are superior. This is because that the number of printing layers required for horizontal and vertical printed samples are not in the same order of magnitude and the probability of accumulating defects along the two directions is quite different. Although the area or length of the layers is different, the number of layers that need to be printed for vertically printed samples is much greater than those of horizontally printed samples. In this way, defects are more likely to form between layers during the laser printing process. Therefore, the volume fraction of defects is larger in vertically printed samples. The anisotropy caused by printing orientation is the fundamental reason for the significant difference in fatigue performance.

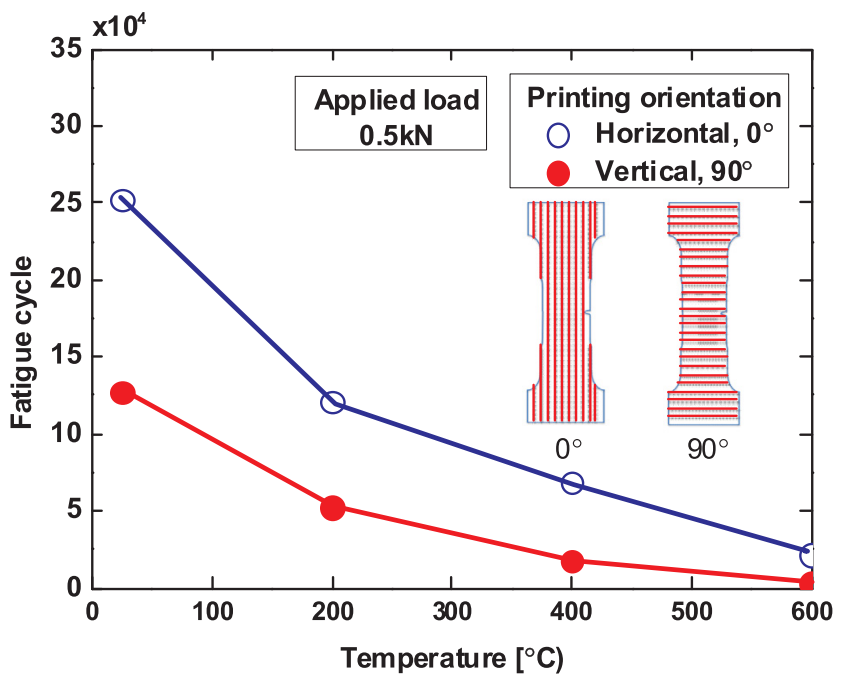

Fig. 12. Relation between fatigue life and the temperature for specimens with different printing orientations.
Notches widely existed in engineering structures and components, which may cause stress concentration. As a result, fatigue crack tends to nucleate at the notch tip and eventually leads to component failure. The quantification of crack propagation rate is of engineering significance. The following is thus focused on the quantification of fatigue propagation for the notched specimens.

According to ASTM, the crack growth length $a$ and the corresponding cycle number $N$ were measured under cyclic loading during crack propagation. The results are shown in Fig. 13. It is seen that the crack length increases with cycle number $N$. The slope of crack length curve increases which indicates that the crack growth rate is increasing. By calculating the linear slope $(\mathrm{d} a / \mathrm{d} N)$ of two adjacent data points on the $a-N$ curve and the corresponding stress intensity factor amplitude, one has

$(d a / d N)_{i}=\left(a_{i+1}-a_{i}\right) /\left(N_{i+1}-N_{i}\right)$

In general, the stress intensity factor is expressed as:

$K=F \sigma \sqrt{\pi a}$

where $a$ is the crack length, $F$ is shape factor.

If short crack appears at the notch root, the interaction between the notch root and the short crack leads to a slightly lower stress intensity factor than expected. Smith and Miller [45] gave the following estimating formulas according to the solution provided by Newman [46]. when $a<0.13 \sqrt{D \rho}$,

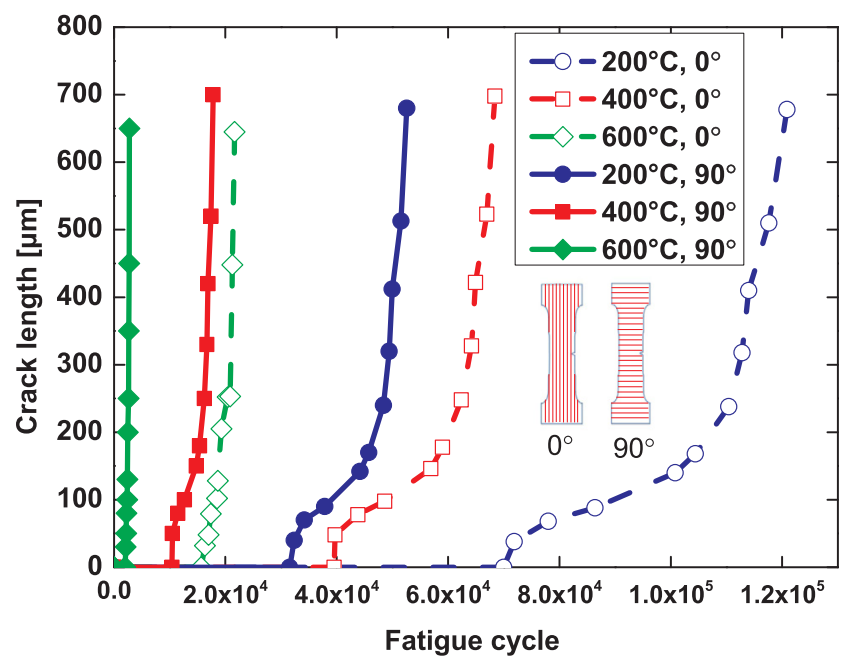

Fig. 13. The relationship between crack length and fatigue cycle number at different temperatures. 


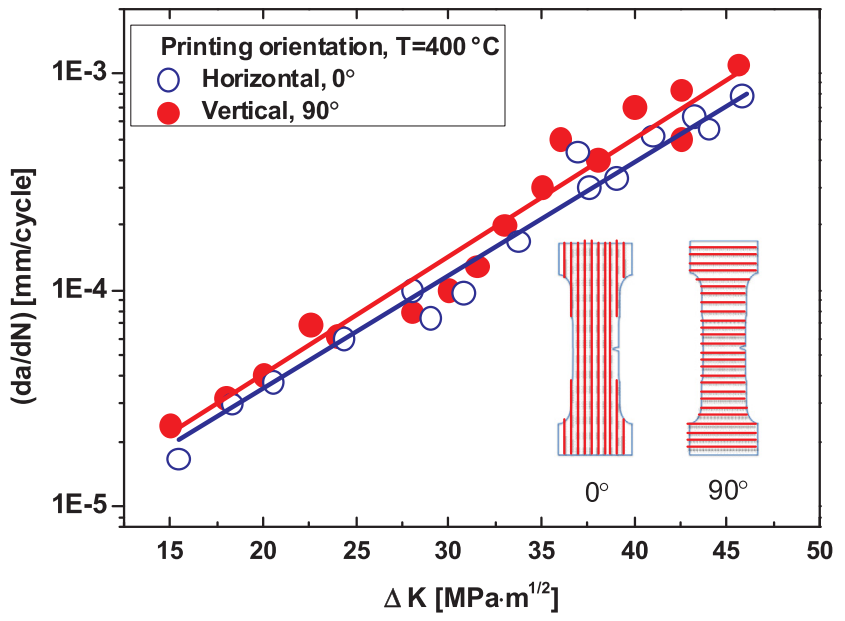

Fig. 14. Crack propagation rate for Ti-6Al-4V specimens manufactured with different orientations.

$\Delta K=\Delta \sigma \sqrt{\pi a} \sqrt{1+7.69 D / \rho}$

when $a>0.13 \sqrt{D \rho}$,

$\Delta K=\Delta \sigma \sqrt{\pi(a+D)}$

where $D$ is the depth of the notch, and $\rho$ is the radius of curvature of the notch root. By using Eq. (1) and (2), $\Delta K$ and $\mathrm{d} a / \mathrm{d} N$ are calculated. Paris formula is then used to correlate $\Delta K$ and $\mathrm{d} a / \mathrm{d} N$, as

$d a / d N=C(\Delta K)^{m}$

where $C$ and $m$ are material constants and $\Delta K$ is the range of stress intensity factor. The results at $\mathrm{T}=400{ }^{\circ} \mathrm{C}$ are well predicted with the Paris model, as shown in Fig. 14. Therefore, it can be used to quantify the crack growth of Ti-6Al-4V manufactured by SLM.

\section{Conclusions}

In this paper, fatigue property and crack propagation mechanism of Ti-6Al-4V specimens manufactured by SLM with different manufacturing orientations were investigated by in-situ test at different temperatures. The main conclusions are as follows:

(1) The fatigue property of horizontally printed specimens is better than that of vertically printed specimens. Vertically printed samples have more and larger defects and unmelted particles than horizontally printed samples. The anisotropy caused by the printing orientation is attributed to the reason for the significant difference in fatigue performance at different temperatures.

(2) Defects formed in the SLM process affect the crack growth behavior. The inhomogeneity of local structures such as defects and inclusions change the crack growth path, reducing the crack growth rate.

(3) The crack growth rate of Ti- $6 \mathrm{Al}-4 \mathrm{~V}$ specimens manufactured by SLM increases with temperature. A large number of secondary cracks occurred during the crack propagation at elevated temperature. The branching of secondary cracks releases the energy at the crack tip, and thus slows down the crack growth.

More studies on biaxial fatigue analysis [47], multiaxial fatigue $[48,49]$ and probabilistic fatigue modeling $[50,51]$ of additive manufactured materials are planned.

\section{Declaration of Competing Interest}

We hereby declare that there is no conflict of interest. This paper (or closely related research) has not been published or accepted for publication. It is not under consideration at another journal.

\section{Acknowledgement}

This work was funded by the National Natural Science Foundation of China (No. 11872364, 11932020) and CAS Pioneer Hundred Talents Program.

\section{References}

[1] Wong K, Hernandez A. A review of additive manufacturing. ISRN. Mech. Eng. $2012 ; 10$.

[2] Liu S, Shin Y. Additive manufacturing of Ti6Al4V alloy: A review. Mater. Des. 2019;164:1-23.

[3] Yadollahi A, Shamsaei N. Additive manufacturing of fatigue resistant materials: challenges and opportunities. Int. J. Fatigue 2017;98:14-31.

[4] Herzog D, Seyda V, Emmelmanna C. Additive manufacturing of metals. Acta Mater. 2016;117:371-92.

[5] Boyer R. An overview on the use of titanium in the aerospace industry. Mater. Sci. Eng. A 1996;213:103-14.

[6] Zhang Y, Wu L, Guo X, Kane S, Deng Y, Jung Y, et al. Additive manufacturing of metallic materials: a review. J. Mater. Eng. Perform. 2018;27:1-13.

[7] Brandl E, Heckenberger U, Holzinger V, Buchbinder D. Additive manufactured AlSi10Mg samples using selective laser melting (SLM): microstructure, high cycle fatigue, and fracture behavior. Mater. Des. 2012;34:159-69.

[8] DebRoy T, Wei H, Zuback J, Mukherjee T, Elmer J, Milewski J, et al. Additive manufacturing of metallic components-process, structure and properties. Prog. Mater. Sci. 2018;92:112-224.

[9] Stéphane G, Christopher H. Additive manufacturing of metals: a brief review of the characteristic microstructures and properties of steels, Ti-6Al-4V and high-entropy alloys. Sci. Technol. Adv. Mater. 2017;18:584-610.

[10] Martin J, Yahata B, Hundley J, Mayer J, Schaedler T, Pollock T. 3D printing of highstrength aluminium alloys. Nature 2017;549:365-9.

[11] Haniyeh F, Mehrnaz S, Allan R. A critical review of powder-based additive manufacturing of ferrous alloys: Process parameters, microstructure and mechanical properties. Mater. Des. 2018;144:98-128.

[12] Tridello A, Biffi C, Fiocchi J, Bassani P, Chiandussi G, Rossetto M, et al. VHCF response of as-built SLM AlSi10Mg specimens with large loaded volume. Fatigue Fract. Eng. Mater. Struct. 2018;41:1918-28.

[13] Pan X, Su H, Sun C, Hong Y. The behavior of crack initiation and early growth in high-cycle and very-high-cycle fatigue regimes for a titanium alloy. Int. J. Fatigue 2018;115:67-78.

[14] Qian G, Zhou C, Hong Y. Experimental and theoretical investigation of environmental media on very-high-cycle fatigue behavior for a structural steel. Acta Mater. 2011;59:1321-7.

[15] AKhairallah S, Anderson A, Rubenchik A, King W. Laser powder-bed fusion additive manufacturing: Physics of complex melt flow and formation mechanisms of pores, spatter, and denudation zones. Acta Mater. 2016;108:36-45.

[16] Buchbinder D, Schleifenbaum H, Heidrich S, Meiners W, Bültmann J. High power selective laser melting (HP SLM) of aluminum parts. Phys. Proce. 2011;12:271-8.

[17] Leung C, Marussi S, Atwood R, Towrie M, Withers P, Lee P. In situ Xray imaging of defect and molten pool dynamics in laser additive manufacturing. Nat. Commun. 2018;9:1-9.

[18] Hiroshige M, Yuzo T. Influence of defects, surface roughness and HIP on the fatigue strength of Ti6Al-4V manufactured by additive manufacturing. Int. J. Fatigue 2018;117:163-79.

[19] Xiong Z, Liu S. Role of melt pool boundary condition in determining the mechanical properties of selective laser melting AlSi10Mg alloy. 740-741 Mater. Sci. Eng. A 2019:148-56.

[20] Jamison L, Frederick MH. In situ defect detection in selective laser melting via fullfield infrared thermography. Addit. Manuf. 2018;24:595-605.

[21] Bastien V, Nicolas S. Numerical modelling of surface roughness effect on the fatigue behavior of Ti-6Al-4V obtained by additive manufacturing. Int. J. Fatigue 2019;123:180-95.

[22] Zhang Q, Xie J. Estimates of the mechanical properties of laser powder bed fusion Ti-6Al-4V parts using finite element models. Mater. Des. 2019;169:1-11.

[23] Victor C, Philippe Q. Comparative study of fatigue properties of Ti-6Al-4V specimens built by electron beam melting (EBM) and selective laser melting (SLM). Mater. Charact. 2018;143:76-81.

[24] Dzugan J, Seifib M. Effects of thickness and orientation on the small scale fracture behaviour of additively manufactured Ti-6Al-4V. Mater. Charact. 2018;143:94-109.

[25] Benedetti M, Fontanari V, Bandini M, Zanini F, Carmignato S. Low- and high-cycle fatigue resistance of Ti-6Al-4V ELI additively manufactured via selective laser melting: mean stress and defect sensitivity. Int. J. Fatigue 2018;107:96-109.

[26] Romano S, Patriarca L, Foletti S, Beretta S. LCF behaviour and a comprehensive life prediction model for AlSi10Mg obtained by SLM. Int. J. Fatigue 2018;117:47-62.

[27] Cai C, Gao X, Teng Q. A novel hybrid selective laser melting/hot isostatic pressing of near-net shaped Ti-6Al-4V alloy using an in-situ tooling: Interfacial microstructure evolution and enhanced mechanical properties. Mater. Sci. Eng. A 2018;717:95-104.

[28] Zhang W, Liu Y. Investigation of incremental fatigue crack growth mechanisms using in situ SEM testing. Int. J. Fatigue 2012;42:14-23.

[29] Lua J, Ling C. In-situ investigation of the anisotropic mechanical properties of laser direct metal deposition Ti6Al4V alloy. Mater. Sci. Eng. A 2018;712:199-205. 
[30] Walker K, Liu Q. Evaluation of fatigue crack propagation behaviour in Ti-6Al-4V manufactured by selective laser melting. Int. J. Fatigue 2017;104:302-8.

[31] Rigon D, Meneghetti G, Görtler M, Cozzi D, Waldhauser W, Dabalà M. Influence of defects on axial fatigue strength of maraging steel specimens produced by additive manufacturing. MATEC Web of Conferences 2018;165:02005.

[32] Rigon D, Formilan V, Meneghetti G. Analysis of the energy dissipation in multiaxial fatigue tests of AISI 304L stainless steel bars. Proce. Struct. Inte. 2018;13:1638-43.

[33] Rigon D, Ricotta M, Meneghetti G. Evaluating the specific heat loss in severely notched stainless steel specimens for fatigue strength analyses. Proce. Struct. Inte. 2018;9:151-8.

[34] Wang Z, Wu W, Qian G, Sun L, Lia X, Correia J. In-situ SEM investigation on fatigue behaviors of additive manufactured Al-Si10-Mg alloy at elevated temperature. Eng. Fract. Mech. 2019;214:149-63.

[35] Han Q, Qiu W, Shang Y, Shi H. In-situ SEM observation and crystal plasticity finite element simulation of fretting fatigue crack formation in Ni-base single crystal super alloys. Tribol. Int. 2016;10:33-42.

[36] Zhang M, Song X. In situ observation of fatigue crack initiation and propagation behavior of a high-Nb TiAl alloy at 750 ${ }^{\circ}$ C. Mater. Sci. Eng. A 2015;622:30-6.

[37] Lu Y, Qiao L. In situ study of martensitic transformation and nucleation and propagation of cracks in Cu-Ni-Al shape memory alloy. Mater. Sci. Tech-Lond. 2002;18:273-8.

[38] Yan J, Hui D. In-situ investigation of tensile deformation and fracture mechanism of 12Cr1MoV steel after long-term service. Mater. Sci. Eng. A 2017;700:33-41.

[39] Gallo P, Sumigawa T, Kitamura T, Berto F. Static assessment of nanoscale notched silicon beams using the averaged strain energy density method. Theor. Appl. Fract. Mech. 2018;95:261-9.

[40] Gallo P, Sumigawa T, Kitamura T. Experimental characterization at nanoscale of single crystal silicon fracture toughness. Frattura ed Integrità Strutturale 2019;47:408-15.

[41] Gallo P, Yan Y, Sumigawa T, Kitamura T. Fracture behavior of nanoscale notched silicon beams investigated by the theory of critical distances. Adv. Theor. Simu. 2017:1-9.

[42] Chai G, Peng R. Fatigue behaviors in duplex stainless steel studied using in-situ SEM/EBSD method. Proce. Mater. Sci. 2014;891-892:1748-53.

[43] GB/T 228-2002. Metallic materials-Tensile testing at ambient temperature, 2002.

[44] Liang J, Wang Z, Xie H, Li X. In situ scanning electron microscopy-based hightemperature deformation measurement of nickel-based single crystal superalloy up to $800{ }^{\circ} \mathrm{C}$. Opt. Laser. Eng. 2018;108:1-14.

[45] Smith R, Miller K. Fatigue cracks at notches. Int. J. Mech. Sci. 1977;19:11-2.

[46] Newman J. An improved method of collocation for the stress analysis of cracked plates with various shaped boundaries. NASA. TND; 1971.

[47] Infante D, Qian G, Miguélez H, Giner E. Analysis of the effect of out-of-phase biaxial fatigue loads on crack paths in cruciform specimens using XFEM. Int. J. Fatigue123 2019:87-95.

[48] Liao D, Zhu S, Qian G. Multiaxial fatigue analysis of notched components using combined critical plane and critical distance approach. Int. J. Mech. Sci. 2019;160:38-50.

[49] Xu S, Zhu S, Hao Y, Qian G. A new critical plane-energy model for multiaxial fatigue life prediction of turbine disc alloys. Eng. Fail. Anal. 2018;93:55-63.

[50] Qian G, Lei W. A statistical model of fatigue failure incorporating effects of specimen size and load amplitude on fatigue life. Phil. Mag. 2019;99:2089-125.

[51] Qian G, Lei W, Peng L, Yu Z, Niffengger M. Statistical assessment of notch toughness against cleavage fracture of ferritic steels. Fatigue Fract. Eng. Mater. Struct. 2018;41:1120-31. 